\title{
Agricultural Marketing and how the Shaffer - Star can be Applied
}

\author{
Ejiro U. Osiobe \\ Founder/CFO of the Ane Osiobe International Foundation \\ New Mexico State University \\ New Mexico, USA \\ Abdulqudus A. Ibrahim \\ Research Associate at the Ane Osiobe International Foundation \\ Bayero University, Kano, Nigeria
}

\begin{abstract}
This study examines the application of Shaffer's - Star model in the distribution of agricultural produce. The paper uses the Ane Osiobe Altruism Farm in Gwagwalada, Federal Capital Territory (FCT) as a case study. The study aims to define the concept of marketing and its application to grow the farm's revenue. Furthermore, the study seeks to review previous research carried out on the farm and apply the Shaffer's - Star in the distribution of the farm output to consumers. From reviewed literature (Osiobe E.U. 2018), and (Enyinnaya J.C. and Osiobe E.U. 2017), it shows that the farm may likely earn $\$ 255.00 \mathrm{k}$ for every $1.00 \mathrm{k}$ invested. However, it is dependent on the efficient utilization of resources such as land, labor, and capital (Eninnaya J.C. and Osiobe E.U. 2017). For this paper, marketing will be delved into because it is an essential strategy in raising more revenue for the Altruism farm, and the distance between the Altruism farm and nearby market(s) would be analyzed using the gravity model. Our results show that market $N$ would be the best place to sell the farm's products as it's ranked as number one, followed by market $G$ and $A$. The rankings are based on the number of commuters' moving in and out of the market, and this reflects the volume of transactions that take place within the market.
\end{abstract}

Keyword: Shaffer Star; Gravity Model; Altruism Farm

\section{Introduction}

Nigeria has practiced non-mechanized agriculture since its independence in 1960. The arable land for agriculture production can be attributed to the nation's climate conditions. The agriculture sector has employed more than $80 \%$ of the Nigerian population, and the famous groundnut pyramids of Kano showed the strength of the agricultural sector's capacity in the 1960s. It was estimated that the remaining $20 \%$ of the population, were involved in small businesses such as pottery, weaving, carving, and tool-making; to support and supplement their livelihood from farming (Adebola and Oguzor, 2009).

An agricultural business enterprise is an economic unit that makes independent decisions to optimize the use of its resources for production and profit maximization. In Nigeria, average small business enterprises make zero economic profit, and at best, they break even after every fiscal year. In siting a farm, it is necessary to look at the following factors which include but are not limited to, proximity to labor, land, market availability, resources, and ease of transportation. The Ane Osiobe Altruism Farms specialize in the production of cassava, groundnut, and fishery located in Gwagwalada, FCT. The main goal of the farm is to produce healthy food for the residence of Gwagawlada, FCT and to raise money from the sale of the products to meet some of the foundation's stated needs:

- To bridge the gap between the students at the special needs school Jabi and the food production in the area by engaging locals in agricultural practices (Eninnaya J.C. and Osiobe E.U. 2017, pp 3).

- To produce healthy nutritious food for students at the Special Needs School, Jabi, FCT and raise some money from the sale of the surplus produce to meet their diverse needs (Eninnaya J.C. and Osiobe E.U. 2017, pp 3).

- To support and grow the local economy of Nigeria. (Osiobe E.U. Sunday's Leadership News Paper, pp13 April 29,2018).

- To create local economic growth and development in the Gwagwalada area by creating jobs and employing the host and neighboring communities. (Osiobe E.U. 2018, pp 5).

In order to achieve the Ane Osiobe's Altruism Farm's goals, it is necessary to adopt the Shaffer's - Star strategy and implement the findings from the gravity model. 


\section{The Shaffer - Star Concept:}

Ron Shaffer developed the Shaffer - Star, to help in solving community economic development problems, practitioners concern(s), and cooperative issues. The star focuses on economic and non-economic actors in the practice of community economic development. The star comprises of six components, which includes:

Markets: This part of the star, deals with economic forces that drive the allocation of economic resources; it refers to the demand and supply of goods and services. It takes into consideration the concept of a business location. The idea of inter-industry linkages, the return to scale, and the agglomeration ideology comes into play.

Decision Making: This part of the star, involves setting and implementing policies that affect economic growth, development, and stability. The decision-making capacity is the ability to distinguish between the economic problem(s) and symptom(s). Effective decision making depends on the leader to draw from all resources available; in other words, effective leadership depends on learning from mistakes and drawing productive decision to manage available resources.

Resources: This part of the star involves the labor, capital, and technology used by the farm in producing output. Labour refers to human capital; capital can be grouped into physical capital, which includes but are not limited to building and machines; and natural capital includes but is not limited to water and land.

Rules: This is an essential part of the star because it governs what is done within the market environment/space. The laws that govern a community stand as gatekeepers into the market. Hence, two major things are to be considered when making new laws and amending old ones. First, does the community influence these rules, and second, do these rules hinder economic growth, development, and stability.

Society: This is the part of the star, that many community economic development practitioners agree on the idea that a certain level of social infrastructure needs to be in place before any commercial development efforts can take place. The Shaffer's star focuses on how societies can come together to promote favorable changes, deal with diverse cultural dynamics, and encourage economic growth, development, and stability.

Space: This is the part of the star, that measures the distance of the firm to the nearest local market. The concept builds on the idea that communities are defined within spatial parameters and communication networks.

The study aims to analyze how the Shaffer's - Star concept can be used to optimize the distribution of the Ane Osiobe's Altruism Farm's production of cassava and fish in Gwagwalada, FCT, NG.

\section{Concept of agricultural marketing:}

Marketing and market are related but not the same. The market is any place or setting that allow buyers and sellers to exchange ownership of goods, services, and information to satisfy customer's needs. According to (Olukosi J.O. and Isitor, A. 1990), Agricultural marketing refers to all activities which direct the ins and outflow of goods and services to the consumer from the producers. In agriculture, there are two types of markets, they are the output and input market. The input market supplies various inputs from the manufacturing firms to the farms, while the output market deals with multiple activities of the crops and livestock products in their marketing channels.

Agricultural marketing involves all business activities participating in the flow of goods and services from the point of production to the final consumer (Kohls.R.L. 1985). (Olukosi J.O. et al., 2005) asserts that an efficient marketing system finds surpluses of agricultural products and brings them to where there are shortages. For communities whose products are mostly export-based, payment plans are used in their economic development programs; marketing is essential for such communities to foster economic growth, development, and stability. Agricultural marketing is faced with different challenges, which include many intermediaries, poor handling, packaging, lack of standardization, storage facilities, market information, and multiplicity of market charges, etc.

\section{Literature review on agricultural marketing:}

Asoguwa B.C and Okwoche V.A.'s (2012) study on Sorghum marketing in Benue, Nigeria, analyzed the market structure, market channel, socio-economic characteristics of respondent, marketing margin, and marketing problem of Sorghum. The paper used primary data samples from 100 randomly selected commuters in Sorghum Benue, Nigeria. The results from the survey showed that for every $\$ 1$ :00k spent in Sorghum market, the market margin was $¥ 0: 34 \mathrm{k}$. The study failed to identify efficient marketing strategies to maximize its market margins, but to improve on this margin, the authors' recommended that an access feeder road should be constructed to reduce the cost associated with marketing and adequate security should be provided to minimize the theft problem in the market. Lawal A.M. et al. (2013) study on cassava processing in Kwara, Nigeria, identified marketing and production constraints, various products that can be produced from cassava, and estimated the cost and benefit analysis in producing cassava in Kwara, Nigeria. 
For the study, the authors' used a four-stage random sampling technique to obtain primary data from 118 respondents. Their results showed that $88.1 \%$ of their sample were female farmers, within the female farmers, $60.20 \%$ had some form of formal education, and the average age within the group was 32 years. The author's analysis revealed that four main cassava products were produced in Kwara, Nigeria due to the high profit margins. These products include garri, flour (lafun), fufu, and starch. The costs and returns analysis revealed that processing cassava to garri gave the highest gross margin even though processing cassava to all the four products was profitable.

\section{Literature from Ane Osiobe International Foundation's past research on the Altruism Farm:}

Previous research works have been carried out on the Ane Osiobe Altruism Farm located at Gwagwalada, FCT, Nigeria. (Eninnaya J.C. and Osiobe E.U., 2017) used an optimization model to estimate cost and returns on the farm selected products, which included cassava, corn, groundnut, and a fish. These products were selected based on (Eninnaya J.C. and Osiobe E.U., 2017) cost and benefit analysis on the farm. The overall goals of the two studies were to maximize the farm's profit. The results from the studies showed that the farm would maximize its profit by producing Cassava and fish. The authors' analysis revealed the second iteration of the constraint's variables were more profitable with a $46 \%$ increase from the base model while the first iteration had a $4 \%$ increase from the base model.

Osiobe E.U. (2018) analyzed the economic impact of the farm on the Nigerian economy. The author used an inputoutput model (IMPLAN) to run his model. The results of the study showed that the farm would have a net positive impact on the Nigerian economy. The author's findings also revealed that the net effect on the first year would be $4,122,761$ and the subsequent year is $\$ 6,159,243.10 \mathrm{k}$ if resources are managed well.

\section{Review of the Shaffer's - Star Model:}

Deller S., in his community development rule mini-article, reflect on community economic development using a system approach to arrange ones thinking. While Ron Shaffer offers six-step known as the Shaffer - Star. Another study carried out by the University of Wisconsin on community development paradigm tilted "the Shaffer star and community capitals." Analyzed new approaches in addressing a community complex system. Shaffer, R.E. et al. (2006) argued that the interdisciplinary approach to community economic paradigm which involves six elements of the Shaffer Star and the integration of economic and non-economic factors in community development is essential to foster economic growth and development.

\section{Data Analysis:}

For this study, the gravity model is employed. The gravity model uses Newton's law to analyze and estimate the relationship between trading in two distinct market places. Using Newton's law as the idea's bedrock, instead of gravitational pull, however, the model uses the degree of interaction between cities, towns, or regions. Newton's law of gravity predicts that bodies which are larger and closer will exert more force. The variables for the gravity model are the size of the market and the distance to the market. For our study, size is measured in population, and the distance is measured in kilometers. The idea in the gravity model is similar to that of Newton's law that is, the larger and closer two places are, to one another, the more friction and interaction/motion they will have on one another.

In the gravity model, the interaction(s) is proportional to the size of the market. Hence, there is a positive relationship between the market size and the interaction in the market. Ceteris paribus, as the population in a market increases, the interaction(s) in that same market also increases. Based on the positive relationship preposition, the interactions in the market are inversely proportional to the distance between them. That is, as the distance gets larger, the expected interaction in a market decrease. 


\section{Figure 1 The Distance between the Ane Osiobe Altruism Farm and Local Markets in FCT, Nigeria.}

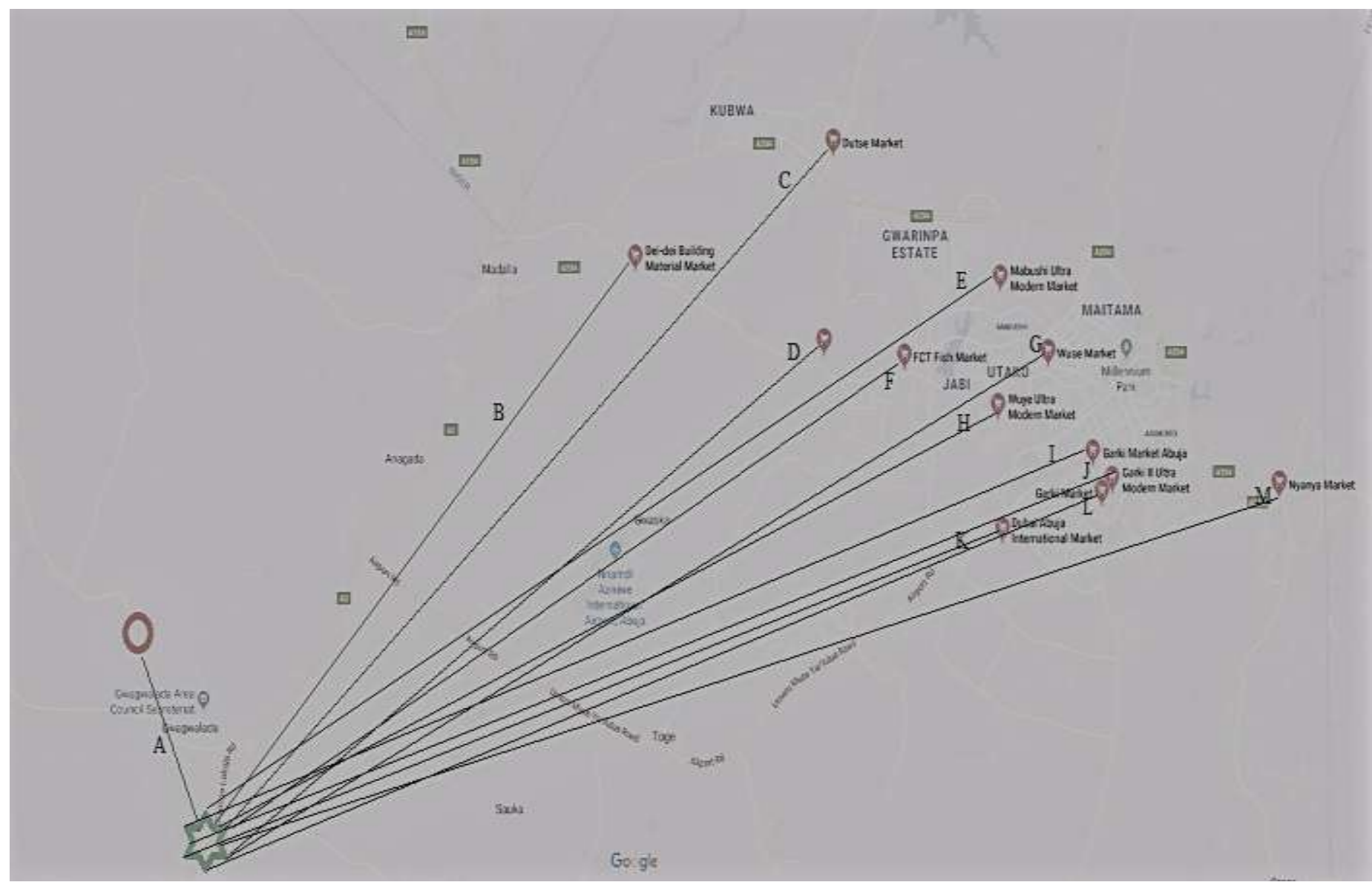

Source: Google Maps

According to the gravity model, the interaction between places is directly proportional to the size of the market and are inversely proportional to the distance to the market.

\begin{tabular}{|c|c|c|}
\hline \multicolumn{3}{|c|}{ Table 1} \\
\hline \# & Kilometer (km) & Market Info \\
\hline $\mathbf{z}$ & $0 \mathrm{~km}$ & Ane Osiobe Altruism Farm a product of Ane Osiobe International Foundation. \\
\hline A & $5.0 \mathrm{~km}$ & Gwagwalada Market, Gwagwalada, Nigeria. \\
\hline B & $32.5 \mathrm{~km}$ & Dei-dei Building Material Market, 102 Inner Northern Road, Abuja, Nigeria. \\
\hline $\mathrm{C}$ & $43.7 \mathrm{~km}$ & Dutse Market, 1 Bwari Express Rd, Abuja, Nigeria. \\
\hline $\mathrm{D}$ & $\begin{array}{l}42.8 \mathrm{~km}, 42.4 \mathrm{~km} \text {, and } 42.1 \\
\mathrm{~km}(\text { Average } 42.4 \mathrm{~km})\end{array}$ & $\begin{array}{l}\text { Karmo Market 1, Idogwari, Abuja, Nigeria; Market 2Idogwari, Abuja, Nigeria; and } \\
\text { Market 3Idogwari, Abuja, Nigeria. }\end{array}$ \\
\hline $\mathrm{E}$ & $56.1 \mathrm{~km}$ & Mabushi Ultra-Modern Market, Kado, Abuja, Nigeria. \\
\hline $\mathrm{F}$ & $56.8 \mathrm{~km}$ & FCT Fish Market, 194/199 ZubaGarki Rd, Gwarinpa, Abuja, Nigeria. \\
\hline G & $56.5 \mathrm{~km}$ & Wuse Market, 24 Wuse Market Rd, Wuse, Abuja, Nigeria. \\
\hline $\mathrm{H}$ & $58.5 \mathrm{~km}$ & Wuye Ultra-Modern Market, 697, 697 Idris Gidado St, Utako, Abuja, Nigeria. \\
\hline I & $57.4 \mathrm{~km}$ & Garki Market Abuja, 7 Awka St, Garki, Abuja, Nigeria. \\
\hline $\mathrm{J}$ & $57.0 \mathrm{~km}$ & Garki II Ultra-Modern Market, 1 Triumph Bank Street, Garki, Abuja, Nigeria. \\
\hline K & $50.5 \mathrm{~km}$ & Dubai Abuja International Market, Kaura, Abuja, Nigeria. \\
\hline $\mathrm{L}$ & $56.3 \mathrm{~km}$ & Garki Market, 22 Samuel Ladoke Akintola Boulevard, Garki, Abuja, Nigeria. \\
\hline M & $70.0 \mathrm{~km}$ & Nyanya Market, Urban Mass Nyanya Market, Nigeria. \\
\hline $\mathrm{N}$ & $41.4 \mathrm{~km}$ & Lugbe Fruit Market, Lugbe, FCT, Nigeria. \\
\hline Sourc & oogle Maps & \\
\hline
\end{tabular}




\section{Formula:}

$$
A=\frac{a \cdot P_{o p} p_{M_{i}} \cdot P_{o p} p_{M_{j}}}{D^{2}}
$$

Where

$A=$ the in and outflow of trade

$a=$ constant

Pop $M_{M_{i}}=$ Market size at base market (Gwagwalada)

Pop $M_{M_{j}}=$ Market size at alternative market $(B-M)$ see figure 1.

$D^{2}=$ distance betweem market size of $M_{i}$ and market size of $M_{j}$

The study implements a Market Population Proxy/Multiple Visit (MPP $P_{M V}$ ) to estimate the number of customer visits into each market. The formula for the $M P P_{M V}$

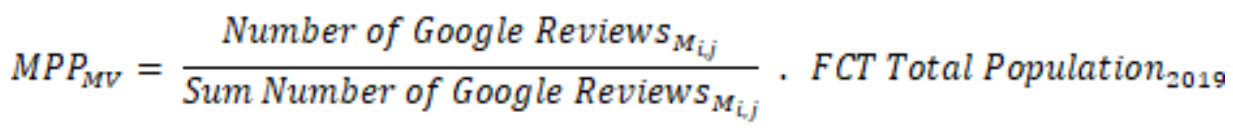

Where: FCT Total Population $2018=3,095,118$

\begin{tabular}{|llllll|}
\hline \multicolumn{2}{l}{ Table 2 Results } & & & \\
Market & $\boldsymbol{P o p}_{\boldsymbol{M}_{\mathbf{i},}}$ & $\boldsymbol{M P P}_{\boldsymbol{M V}}$ & $\boldsymbol{D}^{\mathbf{2}}$ & $\boldsymbol{A}$ & Ranking \\
A & 81 & 13341.03 & 25 & 7119319 & 3 \\
B & 1086 & 179642.9 & 1056.25 & 2268990 & 8 \\
C & 2269 & 398458 & 1909.69 & 2783613 & 7 \\
D & 198 & 39908.4 & 1797.76 & 296156.9 & 13 \\
E & 298 & 60848.74 & 3147.21 & 257937.9 & 14 \\
F & 1010 & 210368 & 3226.24 & 869906 & 10 \\
G & 7929 & 1771927 & 3192.25 & 7405224 & 2 \\
H & 339 & 177207.4 & 3422.25 & 690811.2 & 11 \\
I & 1358 & 752986.4 & 3294.76 & 3048966 & 6 \\
J & 596 & 436716.5 & 3249 & 1793243 & 9 \\
K & 144 & 122849.2 & 2550.25 & 642656.5 & 12 \\
L & 1058 & 939906.7 & 3169.69 & 3956008 & 5 \\
M & 1794 & 2288805 & 4900 & 6231635 & 4 \\
N & 632 & 3095118 & 1713.96 & 24091606 & 1 \\
Source: Authors' calculation & & & & \\
\hline
\end{tabular}

\section{Results:}

Our results show that market $\mathrm{N}$ would be the best place to sell the farm's products as it's ranked as number one, followed by market $\mathrm{G}$ and $\mathrm{A}$. The rankings are based on the number of commuters' moving in and out of the market, and this reflects the volume of transactions that take place within the market. 


\section{Conclusion:}

This study examines the application of the Shaffer's - Star model and how it can be applied in the distribution of agricultural produce. The paper uses the Ane Osiobe Altruism Farm in Gwagwalada, FCT, Nigeria as a case study. The study aims to define the concept of marketing as a section of the Shaffer's - Star and its application to grow the Ane Osiobe Altruism Farm's revenue. Furthermore, the study seeks to review previous research carried out by the foundation on the Altruism Farm "Cost-benefit analysis, optimization, and economic impact study." The study also aims to apply the Shaffer's - Star in the distribution of the farm's output to the final consumers. From the foundation's peer-reviewed literature (Osiobe E.U., 2018), and (Enyinnaya J.C and Osiobe E.U., 2017), it shows that the farm may likely earn $\$ 255.00 \mathrm{k}$ for every $1.00 \mathrm{k}$ invested. However, it is dependent on the efficient utilization of resources such as land, labor, and capital (Eninnaya J.C. and Osiobe E.U., 2017).

The study delved into agriculture marketing because it is an essential strategy in raising more revenue for the Altruism farm, and the distance between the Altruism farm and nearby market(s) was analyzed using the gravity model. Our results show that market $\mathrm{N}$ would be the best place to sell the farm's products as it's ranked as number one, followed by market $\mathrm{G}$ and $\mathrm{A}$.

\section{References:}

Adebola, H.E, and Oguzor, N.S (2009). Gender, Development, and Society. Granada: Afro Euro Centre for Development Studies.

Asoguwa B.C. and Okwoche V.A. (2012). Marketing of agricultural produce among rural farm households in Nigeria: the case of sorghum marketing in Benue state. International Journal of Business and Social Science (vol.3 No.13)

Deller S. University of Wisconsin-madison department of agricultural and applied economics

Ekpa D., Adeola S., Mukhtar U.,and Ekpa M.,(2016). Analysis of processing methods, marketing channels, and profitability determinants of selected cassava products in Kogi state. International Journal of agricultural science, research, and technology in extension and education system. ISSN:2251-7596

Eninnaya J.C and Osiobe E.U. (2017). Cost and return estimates of cassava, groundnut, maize and fish production on the Ane Osiobe altruism farm for the Edison 3.0 project in Gwagwalada, FCT.

Kohls, R. L. (1985). Marketing of Agriculture Products. Macmillan Publishing Company, 866 Third Avenue New 10022

Lawal A.M, Omotesho O.A., and Oyedemi F.A.,(2013). An Assessment of the Economics of Cassava Processing in Kwara State, Nigeria. $4^{\text {th }}$ International conference of the African Association of Agricultural Economics.

Olukosi J.O. and Isitor, A. (1990). Introducing to Agricultural Marketing and Prices: Principles and Application. Abuja: G.U. Publication, pp. 1-3

Osiobe E.U. (2018). The national economic impact from Agriculture: Gwagwalada case study.

Shaffer, R.E., Deller S.C., and Marcouiller D.W. (2006). "Rethinking Community Economic Development." Economic Development Quarterly. 20(1):59-74 